\title{
OPEN Synergistic effect of biological and advanced oxidation process treatment in the biodegradation of Remazol yellow RR dye
}

\author{
Muruganandham Thanavel ${ }^{1}$, Paul Olusegun Bankole $\mathbb{C}^{2 \bowtie}$, Ramu Selvam ${ }^{1}$, \\ Sanjay Prabhu Govindwar ${ }^{3}$ \& Senthil Kumar Sadasivam ${ }^{4}$
}

The current study investigated the efficiency of synergistic biological and Advanced Oxidation Process (AOPs) treatment (B-AOPs) using Aeromonas hydrophila SK16 and AOPs- $\mathrm{H}_{2} \mathrm{O}_{2}$ in the removal of Remazol Yellow RR dye. Singly, A. hydrophila and AOPs showed 90 and $63.07 \%$ decolourization of Remazol Yellow RR dye ( $\left.100 \mathrm{mg} \mathrm{L}^{-1}\right)$ at $\mathrm{pH} 6$ and ambient temperature within $9 \mathrm{~h}$ respectively. However, the synergistic B-AOPs treatments showed maximum decolorization of Remazol Yellow RR dye within $4 \mathrm{~h}$. Furthermore, the synergistic treatment significantly reduced BOD and COD of the textile wastewater by 84.88 and $\mathbf{8 2 . 7 6 \%}$ respectively. Increased levels in laccase, tyrosinase, veratryl alcohol oxidase, lignin peroxidase and azo reductase activities further affirmed the role played by enzymes during degradation of the dye. UV-Visible spectroscopy, Fourier transform infrared spectroscopy (FTIR), high-performance liquid chromatography (HPLC) and gas chromatographymass spectroscopy (GC-MS) confirmed the biotransformation of dye. A metabolic pathway was proposed based on enzyme activities and metabolites obtained after GC-MS analysis. Therefore, this study affirmed the efficiency of combined biological and AOPs in the treatment of dyes and textile wastewaters in comparison with other methods.

Large volume of untreated dyestuffs and wastewaters released into the environment by textile industries pose a great danger to humans, plants and animals ${ }^{1}$. The threats posed by the indiscriminate disposal of dyes to environmental and health safety is attributed to their aromatic nature ${ }^{2}$. Textile wastewater contains dyes, disinfectants, halogen carriers, solvents, toxic heavy metals, carcinogenic amines, chlorine bleaching, biocides, pentachlorophenol, salts, softeners, surfactants, solvents and free formaldehyde ${ }^{3}$. Most manufacturing and allied industries (like food, leather, textile, and paper) make use of azo dyes in their day-day production of goods and products ${ }^{4}$. The remains of dyes are usually visible in shabbily treated textile wastewaters. This, in turn, causes shallow UV light penetration of ocean beds thus leading to poor water quality, low dissolved oxygen and decline in photosynthetic activities ${ }^{5}$.

Conventional physico-chemicals such as membrane filtration ${ }^{6}$, coagulation $^{7}$, adsorption ${ }^{8}$, and chemical oxidation $^{9}$ have proven to biodegrade the dyes in textile effluent. However, the physical and chemical methods come with attendant disadvantages such as toxic residues formation, membrane fouling, bioaccumulation of sludge and formation of secondary pollutants ${ }^{10}$. To further enhance the reduction of toxic amines in the dyes, conventional biological treatment should be incorporated with advanced oxidation process ${ }^{11}$. Sarria et al. ${ }^{12}$ reported that bioremediation of organic pollutants through AOPs in a single treatment is very arduous, relatively costly and sometimes ineffective.

To overcome the limitation, Advanced Oxidation Process (AOPs) is usually combined with biological treatment in the presence of solar radiation for the biodetoxification of textile azo dyes. This method involves the breakdown of the dye constituents followed by removal of toxic aromatic amines ${ }^{13}$. Bacteria like A. hydrophila have proven to be an efficient and promising tool for the removal of textile azo dyes. The use of AOPs enhance

\footnotetext{
${ }^{1}$ Post Graduate and Research Department of Biotechnology, National College (Autonomous), Dindigul Road, Tiruchirappalli, Tamil Nadu 620 001, India. 'Department of Pure and Applied Botany, College of Biosciences, Federal University of Agriculture, P.M.B. 2240, Abeokuta, Ogun State, Nigeria. ${ }^{3}$ Department of Earth Resources and Environmental Engineering, Hanyang University, Seoul 04763, South Korea. ${ }^{4}$ Post Graduate and Research Department of Botany, National College (Autonomous), Dindigul Road, Tiruchirappalli, Tamil Nadu 620001 , India. ${ }^{\varpi}$ email: bankolepo@funaab.edu.ng
} 


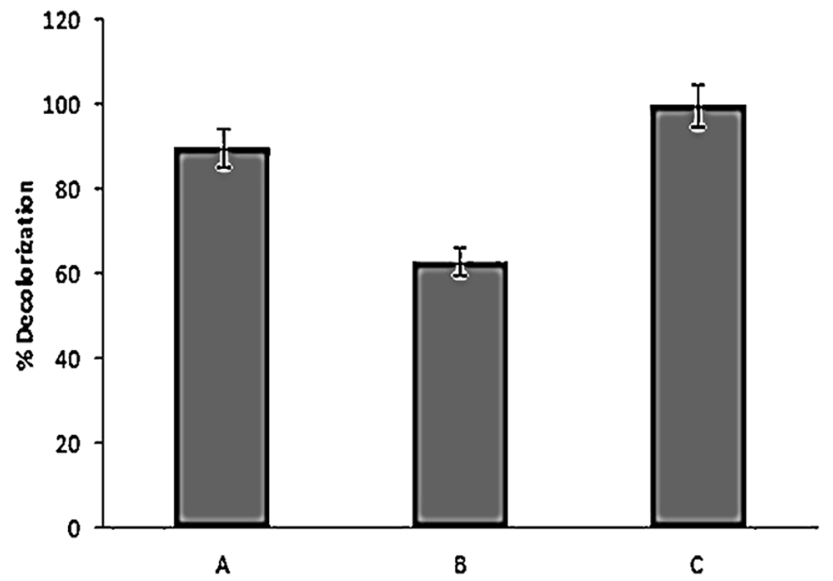

Figure 1. Decolorization percentage of Remazol Yellow RR dye through (a) Biological (b) AOPs (c) Biological + AOPs. Values are plotted as Mean \pm Standard Error of Means $(P \leq 0.05)$. Means were separated with Tukey-b. Drawn with GraphPad Prism software version 8.

biodegradation of textile effluent while bulk reduction of Biological Chemical Demand (BOD) is achieved through biological treatment ${ }^{14}$. Detoxification of dyes is most pronounced of all the biological methods of treatment ${ }^{15}$. Advanced Oxidation Process (AOPs) is usually characterized by the production of radicals (hydroxyl) which are capable of oxidizing aromatic amines in dye wastewater ${ }^{16}$. AOPs are synergistically deployed alongside biological treatment to ensure rapid and efficient textile wastewater treatment ${ }^{17}$. Vilar et al. ${ }^{18}$ suggested the use of sunlight energy systems as Ultraviolet source in the improvement of the oxidation process as an alternative to chemicals. There is paucity of information on the removal of Remazol Yellow RR dye through B-AOPs treatment. Although, different bacteria strains have been deployed in the combined biological and advanced oxidation process (AOPs) treatment of textile dye. However, this is the first report on the degradation of Remazol Yellow RR dye by $A$. hydrophila in combination with AOPs using lesser percentage of hydrogen peroxide.

Hence, this present study is to investigate (1) the potency of biological treatment and advanced oxidation process in the removal of dye (2) determine the enzymes dissipated by A. hydrophila during biodegradation of Remazol Yellow RR dye (3) propose a biochemical pathway of degradation of the dye. The study revealed that the synergistic biotreatment (with bacteria) and advanced oxidation process (solar radiation) of dye has proven to be cheap, cost-effective and eco-friendly.

\section{Results}

Comparison of biological, AOPs and combined biological and AOPs. Maximum decolorization (90\%) of Remazol Yellow RR was achieved by A. hydrophila after $9 \mathrm{~h}$ under static condition (Fig. 1a). At present, there is a paucity of information on degradation of dye mediated by desorption and adsorption. On addition of high amount of $\mathrm{H}_{2} \mathrm{O}_{2}$, Advanced Oxidation Process (AOPs) showed less decolorization (63.07\%) (Fig. 1b) of decolorization. Degradation becomes quite an arduous task when AOPs are deployed singly because of dye's complex aromatic structure and nature. The biologically treated sample was centrifuged at $10,000 \mathrm{rpm}$ for $15 \mathrm{~min}$, and subjected to Advanced Oxidation Process (AOPs) with $4 \% \mathrm{H}_{2} \mathrm{O}_{2}$ for 3-6 h. The significance values obtained for the treatment with bacteria, AOPs and B-AOPs were 0.823, 0.679 and 0.903 which further affirmed the normality of the experimental data on Remazol Yellow RR dye when subjected to Shapiro-Wilk tests. The skewness and kurtosis conducted to test the distribution of the degradation data further affirmed the normality since they were less than 1 and 2 respectively. The significant value obtained was 0.015 when the degradation data was subjected to Levene statistic. This result was able to ascertain the homogeneous nature of the experimental data. One-way Analysis of Variance (ANOVA) revealed that the percentage degradation data of the dye by bacteria, AOPs and B-AOPs were statistically significant at $(P \leq 0.05)$ when the means were separated with Tukey-b. The treatment showed $100 \%$ (Fig. 1c) decolorization within $4 \mathrm{~h}$. After every treatment (biological, AOPs and coupled biological and AOPs) the sample was analyzed by using UV-Vis spectrophotometer in the range of 350-750 $\mathrm{nm}$ (Fig. 2).

Effect of combined treatment (biological, AOPs and B-AOPs) on removal of biological oxygen demand (BOD) and chemical oxygen demand (COD). To ascertain the potency of the combined treatment, all treated samples were tested for reduction in BOD and COD. After completion of AOPs treatment, BOD and COD was reduced by 18 and $34.61 \%$ respectively. In biologically treated sample, 72.08 and $66.76 \%$ in BOD and COD reduction respectively while 84.88 and $82.76 \%$ reduction in BOD and COD was achieved when the treated sample were subjected to combined B-AOPs treatment (Fig. 3). One-way ANOVA revealed that the removal of BOD and COD under synergistic treatment was significantly different $(P \leq 0.05)$ in comparison with individual treatment with bacteria and advanced oxidation process. 


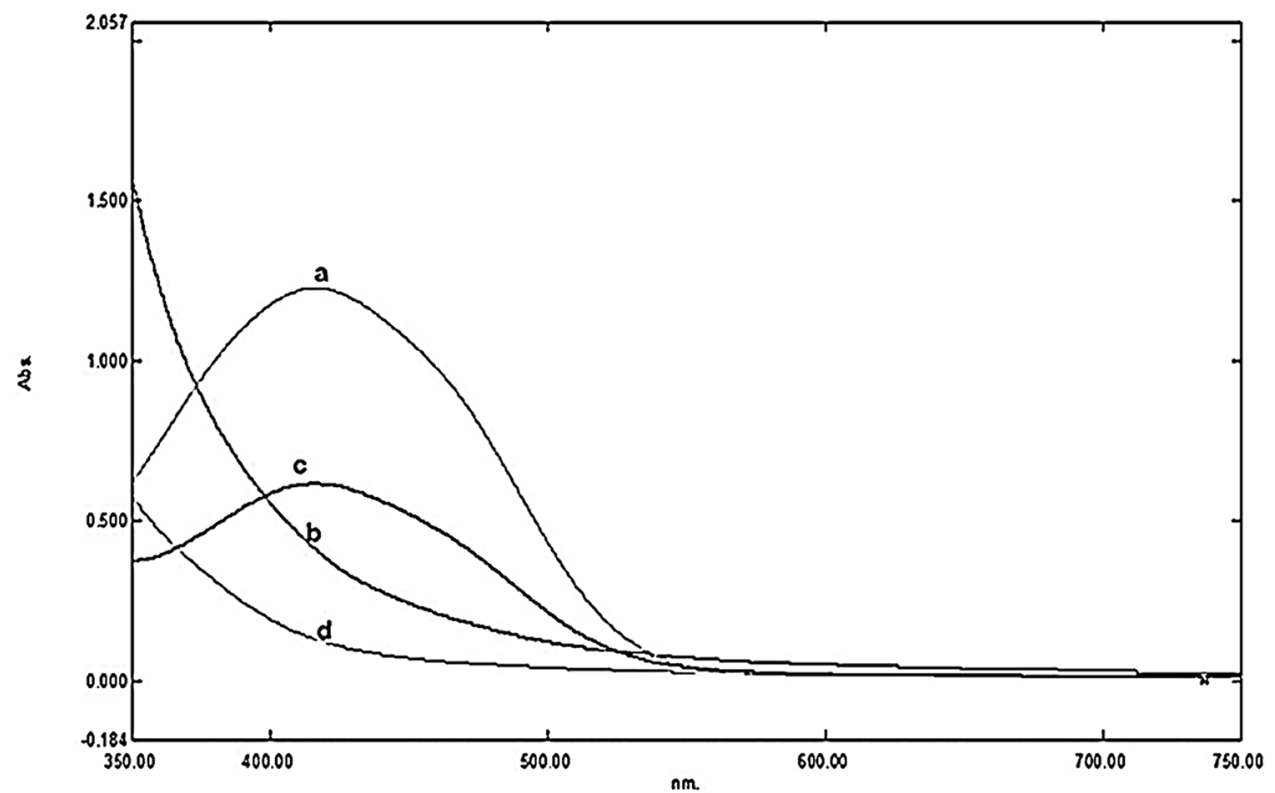

Figure 2. UV-Vis Spectrophotometric analysis of Remazol Yellow RR dye (a) Control (b) Biological (c) AOPs (d) Biological + AOPs.

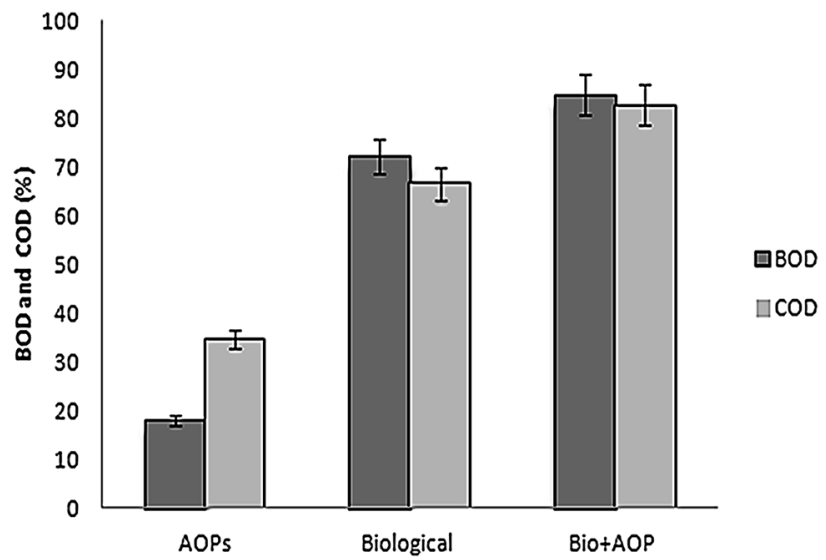

Figure 3. Combined biological and AOPs treatment effects on dye's BOD and COD. Values plotted as Mean \pm Standard Error of Means $(P \leq 0.05)$. Means were separated with Tukey-b. Drawn with GraphPad Prism software version 8 .

Enzyme activities during decolorization of Remazol Yellow RR dye. Enzyme studies revealed the role played by laccase, tyrosinase, veratryl alcohol oxidase, azo reductase and lignin peroxidase during biodegradation of Remazol Yellow RR. At the end of the decolorization experiment, 194.11, 352.49, 11.53, 288.95 and $198.63 \mathrm{U} \mathrm{mL}^{-1} \mathrm{~min}^{-1}$ of veratryl alcohol oxidase, laccase, tyrosinase and lignin peroxidase was induced. In addition, $148.63 \mu \mathrm{mol} \mathrm{NADH}$ reduced $\mathrm{min}^{-1} \mathrm{mg}$ protein ${ }^{-1}$ of azo reductase was significantly induced induction after decolorization experiment. The result represents $89.87,56.50,47.82,75.10$ and $75.87 \%$ inductions in veratryl alcohol oxidase, laccase, tyrosinase and lignin peroxidase and azo reductase activities respectively after complete decolorization of Remazol Yellow RR (Table 1). The skewness and kurtosis of dye degradation by the bacteria, AOPs and B-AOPs were $0.823,0.679$ and 0.903 . This suggests that the data were normally distributed since they were less than 1 and 2 respectively. The significant value $(0.019)$ was observed when the data was subjected to Levene statistic which affirmed the homogeneity in the variances in enzymes induction data. One-way ANOVA revealed substantial significant difference $(P \leq 0.05)$ in all the enzyme activity tests before and after treatment of the dye with A. hydrophila when the means were separated with Tukey-b. Laccase activities was found to be the highest while tyrosinase enzyme was least secreted during the decolorization experiment. Our finding revealed pivotal role played by enzymes in enhancing the decolorization of the dye. 


\begin{tabular}{|l|l|l|}
\hline Enzymes & Before decolorization & After decolorization \\
\hline Veratryl alcohol oxidase $^{\mathrm{a}}$ & $124.03 \pm 0.59$ & $194.11 \pm 0.56^{\star}$ \\
\hline Laccase $^{\mathrm{a}}$ & $185.64 \pm 0.01$ & $352.49 \pm 1.51^{\star}$ \\
\hline Tyrosinase $^{\mathrm{a}}$ & $7.80 \pm 0.05$ & $11.53 \pm 0.09^{\star}$ \\
\hline Lignin peroxidase $^{\mathrm{a}}$ & $165.02 \pm 0.21$ & $288.95 \pm 0.16^{\star}$ \\
\hline Azo reductase $^{\mathrm{b}}$ & $84.51 \pm 0.66$ & $148.63 \pm 0.34^{\star}$ \\
\hline
\end{tabular}

Table 1. Enzyme activities in Remazol Yellow RR before and after dye degradation by A. hydrophila SK 16. Data presented are mean \pm standard error of means of three replicate experiments. ${ }^{\star} P \leq 0.05$. ${ }^{a}$ Activity in $\mathrm{U} \mathrm{mL} L^{-1} \mathrm{~min}^{-1}$. ${ }^{\mathrm{H}} \mu \mathrm{mol}$ NADH reduced $\mathrm{min}^{-1} \mathrm{mg}_{\text {protein }}{ }^{-1}$.
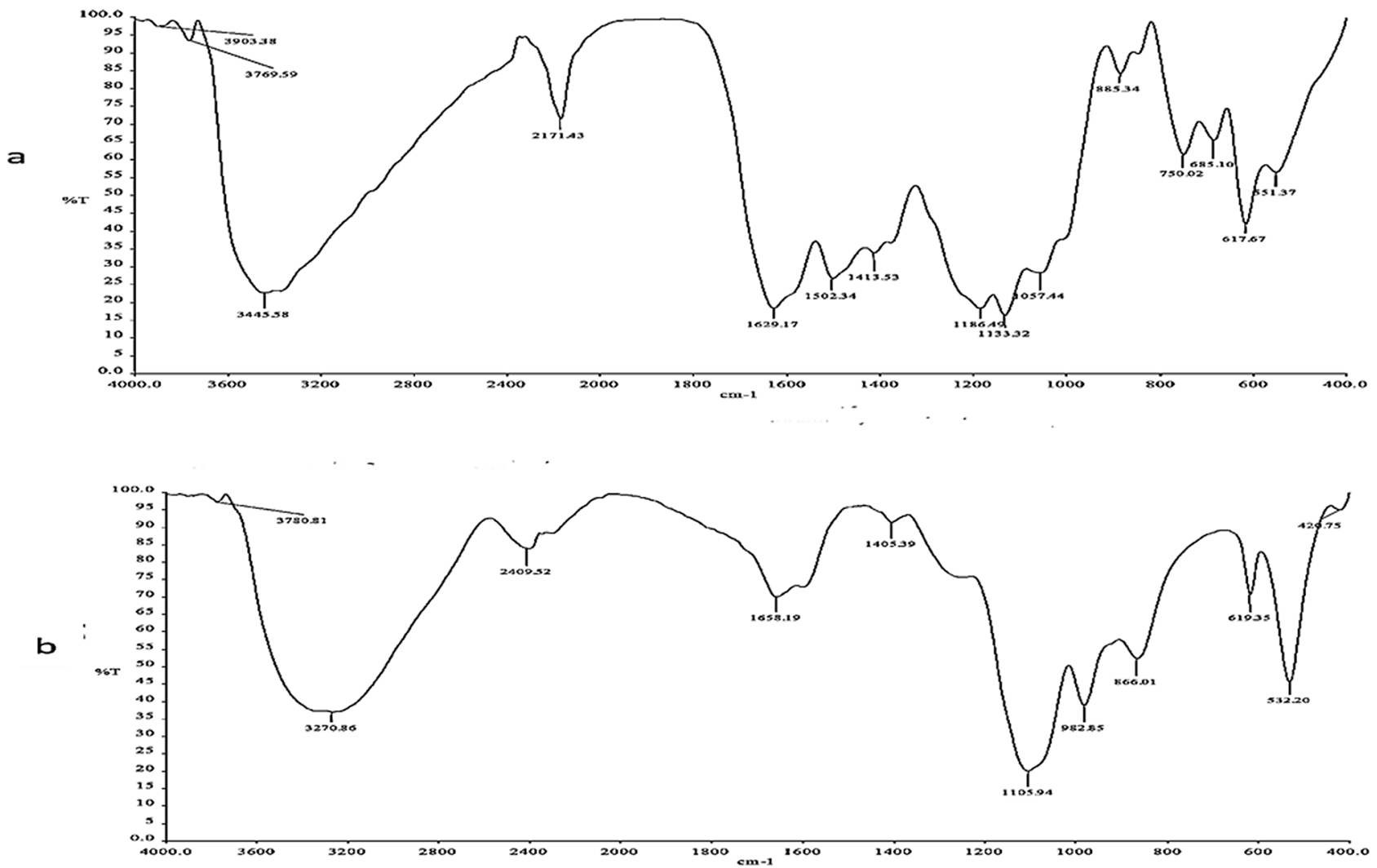

Figure 4. FTIR analysis of Remazol Yellow RR (a) control dye (b) metabolites.

Characterization of dye metabolites with Fourier transform infrared spectroscopy (FTIR), high-performance liquid chromatography (HPLC) and gas-chromatography mass spectrometry (GC-MS) analysis. FTIR spectrum of Remazol Yellow RR showed peaks at 3445, 1629, 1502, 1413, $1186,1133,1057,885,750,685$, and $617 \mathrm{~cm}^{-1}$ which represents to the presence of $\mathrm{N}-\mathrm{H}$ stretching, $\mathrm{N}=\mathrm{N}$ (azo bond), $\mathrm{N}=\mathrm{O}$ stretching, $\mathrm{CH}_{3}$ deformation, $\mathrm{S}=\mathrm{O}$ symmetric stretching sulphonic acid, $\mathrm{C}-\mathrm{O}$ stretching, $\mathrm{C}-\mathrm{N}$ stretching, $\mathrm{C}-\mathrm{H}$ stretching, $\mathrm{C}-\mathrm{Cl}$ stretching (chlorine group), $\mathrm{C}-\mathrm{H}$ deformation, $\mathrm{C}-\mathrm{S}$ stretching sulphur group (Fig. 4a). Products (metabolites) obtained upon biodegradation (total) of Remazol Yellow RR by A. hydrophila SK16 showed disappearance of major peaks and formation of several new peaks at 3270, 1658, 1405, 1105, 982, 866 , and $619 \mathrm{~cm}^{-1}$ which represents to $\mathrm{O}-\mathrm{H}$ stretching, $\mathrm{C}=\mathrm{C}$ stretching, $\mathrm{N}=\mathrm{O}$ bend, $\mathrm{C}-\mathrm{OH}$ stretching, $\mathrm{CH}_{2}$ stretching, C-H stretching and C-H bend (Fig. 4b).

HPLC analysis further confirmed appearance of various metabolites from control dye. Control sample showed a major peak at 2.029 min retention time (Fig. 5a), whereas biodegraded sample showed 5 new peaks with retentions times (1.574, 1.766, 1.867, 3.240 and 3.930 min respectively) (Fig. 5b). The HPLC analysis confirmed the single major peak in the control Remazol Yellow RR dye has been biodegraded into different peaks (five-5) evidently shown by the times (retention). This analysis further affirmed the degradation of the dye.

Remazol Yellow RR dye metabolites after biodegradation by A. hydrophila SK16 was analyzed using Gas Chromatography and Mass Spectroscopy (GCMS) elucidated with peaks in mass spectra (data not shown). Primarily, veratryl alcohol oxidase carried symmetric cleavage of Remazol Yellow RR which yielded Intermediate [I] and Intermediate [II]. Desulfonation of Intermediate [I] gave rise to sodium 2-(3-hydrazinyl-4-methoxyphenyl) ethanolate with the retention time $(16.08 \mathrm{~min})$ and peak $(\mathrm{mw}=204 ; \mathrm{m} / \mathrm{z}=207)$, followed demethylation resulted 
$\mathrm{mV}$

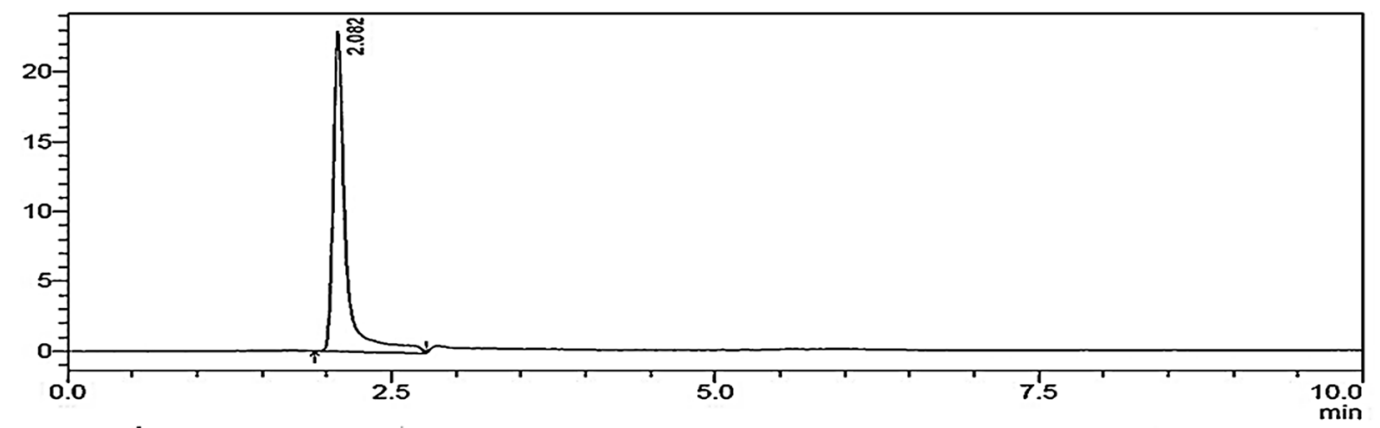

$m \vee$

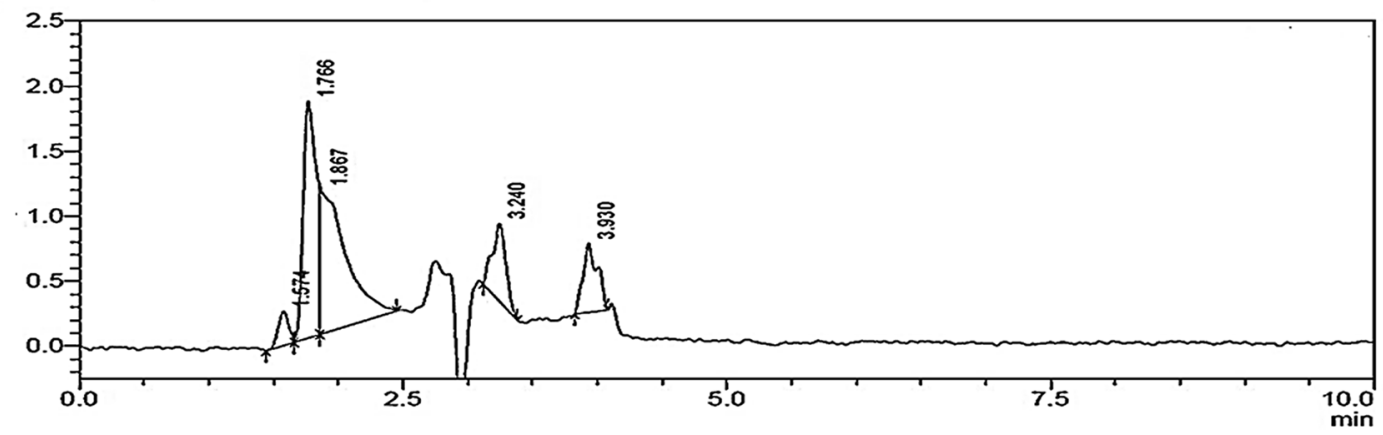

Figure 5. HPLC spectra peaks of Remazol Yellow RR dye (a) control sample (b) metabolite.

in the formation of 2-methoxy-5-methylphenyl)hydrazine with a retention time $(22.20 \mathrm{~min})$ and peak $(\mathrm{mw}=152$; $\mathrm{m} / \mathrm{z}=154)$. Further, deamination provided 2 -methoxy-5-methylaniline with the retention time of $(17.81 \mathrm{~min})$ and peak $(\mathrm{mw}=137 ; \mathrm{m} / \mathrm{z}=136)$, followed deamination resulted in the formation of 1-methoxy-4-methylbenzene with a retention time $(21.09 \mathrm{~min})$ and peak $(\mathrm{mw}=122 ; \mathrm{m} / \mathrm{z}=123)$, followed demethylation resulted in the formation of methylbenzene with a retention time $(13.97 \mathrm{~min})$ and peak $(\mathrm{mw}=92 ; \mathrm{m} / \mathrm{z}=91)$. Symmetric cleavage of Intermediate [II] by laccase resulted in the formation of Intermediate [III] identified as 5-methyl-2,4-dihydro$3 \mathrm{H}$-pyrazol-3-one with retention time $(14.39 \mathrm{~min})$ and peak $(\mathrm{mw}=98 ; \mathrm{m} / \mathrm{z}=99)$ and Intermediate [IV]. Further, demethylation of Intermediate [III] resulted in the formation of 2,4-dihydro-3H-pyrazol-3-one with a retention time of 10.37 and peak $(\mathrm{mw}=84 ; \mathrm{m} / \mathrm{z}=86)$. Desulfonation of intermediate [IV] provided 1-chloro-3-methylbenzene with the retention time $(15.14 \mathrm{~min})$ and peak $(\mathrm{mw}=126 ; \mathrm{m} / \mathrm{z}=125)$, followed demethylation resulted in the formation of chlorobenzene with the retention time $(13.26 \mathrm{~min})$ and a mass peak $(\mathrm{mw}=112 ; \mathrm{m} / \mathrm{z}=111)$. A possible metabolic pathway was proposed for Remazol Yellow RR by A. hydrophila SK16 (Fig. 6).

\section{Discussion}

The UV-Vis spectral results revealed that synergistic treatment with A. hydrophila and AOP accounted for the total disappearance of the major peak in Remazol Yellow RR dye (control) than individual treatment with the bacteria and AOP respectively. Kalme et al. ${ }^{19}$ implied in an earlier work that low decolorization efficiency in aerobic state is due to the interplay of molecular forces between oxygen and azo compounds. Similar results were reported by Kalyani et al. ${ }^{20}$ when Pseudomonas sp. SUK1 was deployed in dye degradation. The power of microbial cells to adsorb dye accounted for decolorization efficiency over a period ${ }^{20}$. Albeit, biodegradation via oxidation (chemical) is very expensive due to the oxidation intermediates produced during treatment. Furthermore, the intermediates are more resistant to complete chemical oxidation and furthermore consume energy relative to treatment time ${ }^{21}$. Harrelkas et al. ${ }^{22}$ reported that it is highly efficient if biological treatment is incorporated to OAPs in order to enhance overall treatment efficiency. First biological treatment decreases concentration of compounds that may compete for chemical oxidation, thus increasing efficiency and lowering treatment $\operatorname{cost}^{23}$. In non-biodegradable textile effluent, the coupled treatment not only achieves efficient decolorization, but also significantly reduces BOD, COD and TDS ${ }^{24}$. The findings in this study revealed higher decolorization potency than the efficiencies recorded by Tantak and Chaudhari ${ }^{25}$ when Reactive Blue 13 and Reactive Blue 5 was subjected to combined B-AOPs treatment. However, this study corroborated the findings of Lodha and Chaudhari ${ }^{26}$ who reported $99 \%$ removal of color when different dye solutions were subjected to combined AOPs and biological treatment. Furthermore, this study was in agreement with the reports of Alvares et al. ${ }^{27}$ on the efficiency of combined B-AOPs in the removal of colors in textile wastewaters. The desulfonation, demethylation and asymmetric cleavage which led to the production of metabolites of Remazol Yellow RR dye as depicted in the metabolic pathway (proposed) was facilitated by high induction of laccase during degradation. The reports on biodegradation of Reactive Red 2 by Kalyani et $\mathrm{al}^{20}$ further corroborated the pivotal role played by laccase. Furthermore, these results were in agreement with previous reports of Parshetti et $\mathrm{al}^{28}$ who revealed the crucial role played by NADCH-DCIP reductase and laccase in the removal of malachite green by Kocuria rosea. Evidently, the spectra analysis (FT-IR) of the metabolites showed disappearance and proliferation of new peaks which are different from the peaks observed in the control (Remazol Yellow RR) dye. The structural changes in the fingerprint and functional group regions of the Remazol Yellow RR dye spectra strongly suggests 


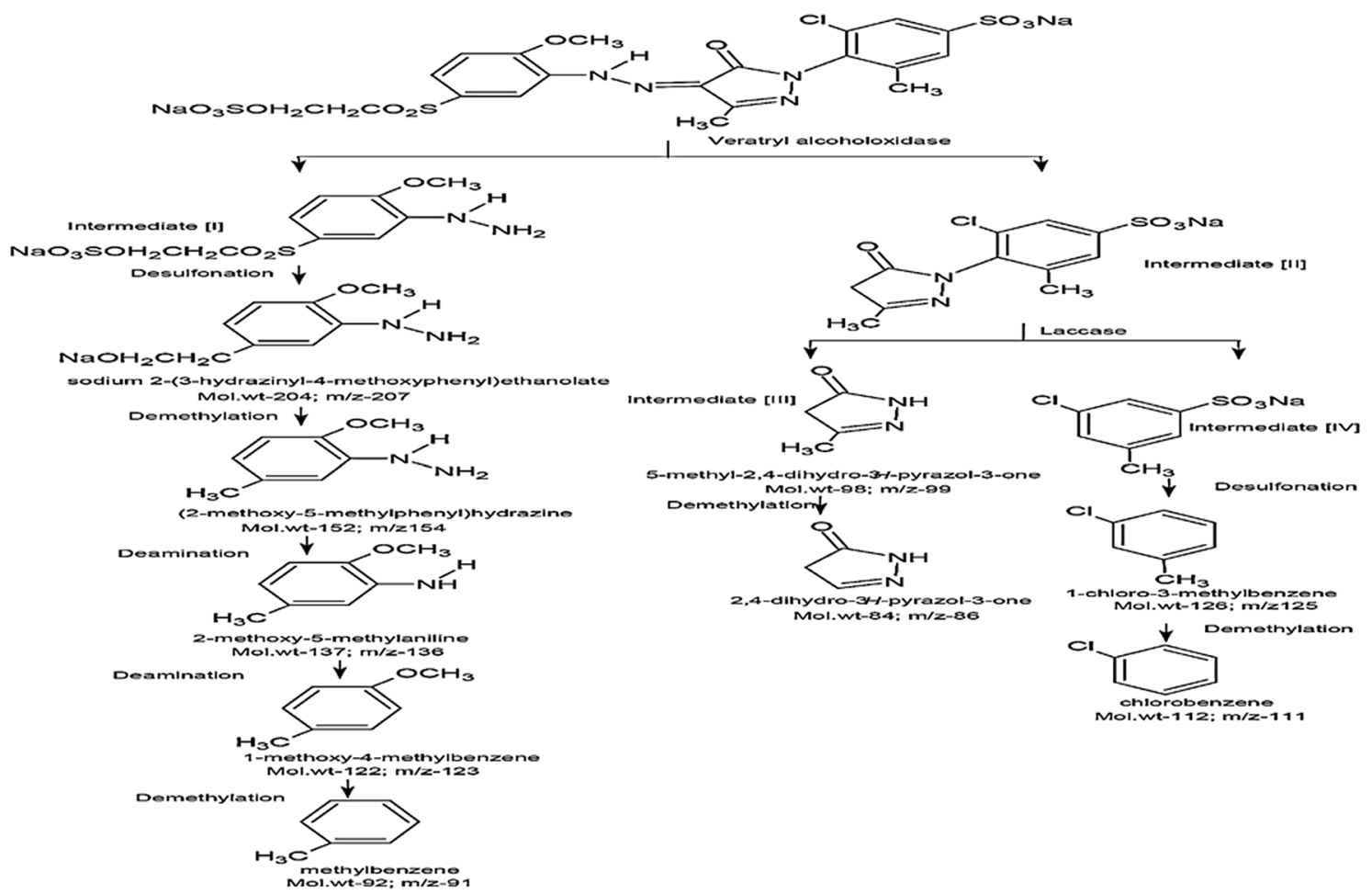

Figure 6. Metabolic pathways for Remazol Yellow RR biodegradation by A. hydrophila SK16. Drawn with ChemSketch software version 11.02 .

biodegradation. In addition, formation of new peaks formed at different retention times in the treated Remazol Yellow RR dye HPLC spectrum equally affirmed the breakdown of dye. These results were corroborated the reports of Jadhav et $\mathrm{al}^{5}$.

\section{Methods}

Dyes and chemicals. Remazol Yellow RR dye was obtained from Tamil Nadu, India (Jamara textile industry). Veratryl alcohol, methyl red, L-ascorbic acid, Catechol and nutrient broth were obtained from Pvt Laboratories (Hi Media), Mumbai. Hydrogen peroxide was procured from Merck Mumbai. Other reagents used were of high purity and analytical grade.

Culture maintenance and decolorization. Aeromonas hydrophila SK16 used in the present work was isolated previously in our laboratory from textile contaminated soil ${ }^{29}$. The culture was maintained at $4^{\circ} \mathrm{C}$ on nutrient agar slant (Nutrient Agar: NaCl-5 g, Beef extract-1.5 g, Yeast extract-1.5 g, and Agar-15 g). Decolorization study was carried out in Erlenmeyer flask $(250 \mathrm{~mL})$ containing nutrient broth of aforementioned composition. The dye $\left(100 \mathrm{mg} \mathrm{L}^{-1}\right)$ was added to a pre-grown culture of $A$. hydrophila and incubated at $37^{\circ} \mathrm{C}$ under static condition. The $\mathrm{pH}$ was adjusted to 8 in pre-grown culture with the addition of $\mathrm{NaOH}$. A $5 \mathrm{~mL}$ aliquot was withdrawn at regular intervals, centrifuged at $10,000 \mathrm{rpm}$ for $15 \mathrm{~min}$ and decolorization was monitored with UV-Vis Spectrophotometer (Shimadzu 1800) at wavelength $\left(\lambda_{\max }=560 \mathrm{~nm}\right)$. The control experiments were made of flasks with no bacteria cells. All the experiments were performed in triplicates. Decolorization percentage was calculated using the formula:

$$
\text { Decolorization }(\%)=\frac{\text { Initial absorbance }- \text { Final absorbance }}{\text { Initial absorbance }} \times 100
$$

Experiments on advanced oxidation process (AOPs). The AOPs was carried out in Erlenmeyer flask $(250 \mathrm{~mL})$ containing Remazol Yellow RR dye $\left(100 \mathrm{mg} \mathrm{L}^{-1}\right)$ with $4 \%$ hydrogen peroxide. The percentage of $\mathrm{H}_{2} \mathrm{O}_{2}$ used for this study was based on the initial screening done with variations from 1 to $10 \%$. The setup was placed for $6 \mathrm{~h}$ under UV radiation. This procedure was repeated in dark conditions. The control experiment was made of flasks with no $\mathrm{H}_{2} \mathrm{O}_{2}$. The light intensity was monitored with Lux meter (Lutron LX-101, Taiwan).

Biological and advanced oxidation process (AOP) treatment. The biodegraded sample was centrifuged at 10,000 rpm for $15 \mathrm{~min}$. The supernatant was subjected to AOPs with $4 \% \mathrm{H}_{2} \mathrm{O}_{2}$ for 3-6 h. Lux meter (Lutron LX-101, Taiwan) was used to measure Light intensity. The sample was thereafter analyzed with UV-Vis spectrophotometer (Shimadzu 1800, Japan). 
Characterization of Remazol Yellow RR. Biological Oxidation Demand (BOD) and Chemical Oxidation Demand (COD) of Remazol Yellow RR were characterized before and after dye degradation ${ }^{30}$.

Cell-free extract preparation for enzyme assays. Bacterial cells were cultured in nutrient broth for $24 \mathrm{~h}$ and centrifuged at 10,000 rpm for $15 \mathrm{~min}$. The supernatant was removed and the bacterial cells $\left(75 \mathrm{mg} \mathrm{L}^{-1}\right)$ were suspended in potassium phosphate buffer $(50 \mathrm{mM}, \mathrm{pH} 7.4)$, homogenized in a glass homogenizer and sonicated (sonics-vibracell) at 40 amplitude at $4{ }^{\circ} \mathrm{C}$ and giving 8 strokes, each of $40 \mathrm{~s}$ with $2 \mathrm{~min}$ interval. This sample was used for enzyme studies without further centrifugation. Control experimental set up contains no dye.

Enzyme assays. Activities of laccase and veratryl alcohol oxidase were assayed spectrophotometrically by using UV-Vis spectrophotometer (Shimadzu 1800, Japan). The total volume of $2 \mathrm{~mL}$ was contained $1 \mathrm{mM}$ veratryl alcohol, citrate buffer $(\mathrm{pH} 3)-0.1 \mathrm{M}$ and $0.2 \mathrm{~mL}$ enzyme source. This was done to determine veratryl alcohol oxidase. Oxidation of veratryl alcohol was monitored by increasing of absorbance at $310 \mathrm{~nm}$ due to formation of propanaldehyde ${ }^{31}$. Laccase activity was determined in a $2 \mathrm{~mL}$ of reaction mixture containing $10 \%$ of ABTS in $20 \mathrm{mM}$ potassium phosphate buffer $(\mathrm{pH} 4)$ and the increased optical density was measured at $420 \mathrm{~nm}^{32}$. Lignin peroxidase assay was performed in a total $2.5 \mathrm{~mL}$ volume comprising tartaric acid $(250 \mathrm{mM})$ and n-propanol $(100 \mathrm{mM})$. The propanaldehyde production was estimated at $300 \mathrm{~nm}$ as reported by Kalyani et al. ${ }^{20}$. Tyrosinase activity was calculated in a reaction mixture of $2 \mathrm{~mL}$, containing in $0.1 \mathrm{M}$ phosphate buffer $(\mathrm{pH} 7.4)$ with $0.01 \%$ catechol at $495 \mathrm{~nm}^{24}$. Azoreductase assay was carried out using Methyl red as substrate as reported by Kurade et al..$^{33}$.

Extraction and analysis of metabolites produced during biodegradation. After complete biodegradation, the set up was centrifuged (at 10,000 rpm for $15 \mathrm{~min}$ ). Ethyl acetate was proportionately mixed with the supernatant in order to extract the metabolites produced during biodegradation. Rotary evaporator was used to dry the extracts over anhydrous $\mathrm{Na}_{2} \mathrm{SO}_{4}$. The dried sample was dissolved in HPLC grade methanol and used for analytical studies. The changes of surface functional groups of Remazol Yellow RR before and after biodegradation was investigated by using FTIR Perkin Elmer (RX I $)^{34}$. HPLC analysis was conducted using Jadhav et al. ${ }^{5}$ method. The Shimadzu LC 40,102,010 instrument was used for HPLC study connected with C18 column. The solvent methanol was used in mobile phase with $1 \mathrm{~mL} \mathrm{~min}^{-1}$ flow rate and analysis was done at $470 \mathrm{~nm}^{23}$.

Gas Chromatography (GC)-45XGC-44 coupled with Scion MS-40 Mass Spectroscopy (Bruker) was used in analyzing metabolites obtained after biotransformation. Voltage of $(70 \mathrm{eV})$ was used while the carrier gas was made of helium with $1 \mathrm{~mL} \mathrm{~min}{ }^{-1}$ (flow rate) and $26 \mathrm{~min}$ (duration). DB-WAX column $(0.25 \mathrm{~mm}-30 \mathrm{~mm}$ ) was used for the GC analysis initially set at the operating temperature mode. The column (oven) temperature was increased steadily by $10^{\circ} \mathrm{C}$ per minute to $250^{\circ} \mathrm{C}$. The operating condition was kept for $26 \mathrm{~min}$. from the initially programmed temperature of $80^{\circ} \mathrm{C}$. ChemSketch software version 11.02 was deployed in sketching the metabolic products, hence the pathway (proposed) while the metabolites were identified based on comparison with mass spectra available in the NIST database.

Statistical analysis. All experiments were performed in triplicates. Data and graphs were presented as Mean \pm Standard Error of Means at $95 \%$ Confidence Interval. Normality and homogeneity of variances of the data on Remazol Yellow dye degradation and enzymes induction were conducted with Shapiro-Wilk and Levene statistic tests respectivel ${ }^{35}$. One-way Analyses of Variance (ANOVA) was carried out to affirm the homogenous nature of the data on degradation of dye and enzyme induction. Statistical analysis (ANOVA) $(P \leq 0.05)$ and graphs was performed with GraphPad Prism software version $8^{35}$.

\section{Conclusion}

The synergistic effect of Advanced Oxidation Process (AOPs) and biological treatment developed by incorporating A. hydrophila SK16 and $4 \% \mathrm{H}_{2} \mathrm{O}_{2}$ for Remazol Yellow RR dye biodegradation was reported. This combined treatment achieved $100 \%$ decolorization, $84.88 \%$ BOD and $82.76 \%$ COD reduction. The biodegradation process elucidated substantial induction of laccase and veratryl alcohol oxidase. UV-vis spectroscopy, FTIR, HPLC and GC-MS analysis proved that degradation of Remazol Yellow RR by A. hydrophila SK16. Therefore, the combined $\mathrm{B}$-AOPs provides cost effective, non-energy demanding and ecofriendly treatment for managing textile dye pollution in the environment.

\section{Data availability}

All experimental data would be made freely available and accessible upon request by the corresponding author.

Received: 21 July 2020; Accepted: 23 October 2020

Published online: 19 November 2020

\section{References}

1. Allen, S. J. \& Koumanova, B. Decolourisation of water/wastewater using adsorption (review). J. Univ. Chem. Technol. Metall. 40, 175-192 (2005).

2. Bidhendi, G. R. N., Torabian, A., Ehsani, H. \& Razmkhah, N. Evaluation of industrial dyeing wastewater treatment with coagulants and polyelectrolyte as a coagulant aid. Iran J. Environ. Health Sci. Eng. 4, 29-36 (2007).

3. Jadhav, S. B., Chougule, A. S., Shah, D. P., Pereira, C. S. \& Jadhav, J. P. Application of response surface methodology for the optimization of textile effluent biodecolorization and its toxicity perspectives using plant toxicity, plasmid nicking assays. Clean Technol. Environ. 17, 709-720. https://doi.org/10.1007/s10098-014-0827-3 (2015). 
4. Khehra, M. S., Saini, H. S., Sharma, D. K., Chadha, B. S. \& Chimni, S. S. Comparative studies on potential of consortium and constituent pure bacterial isolates to decolorize azo dyes. Water Res. 39, 5135-5141. https://doi.org/10.1016/j.watres.2005.09.033 (2005).

5. Jadhav, S. B., Phugare, S. S., Patil, P. S. \& Jadhav, J. P. Biochemical degradation pathway of textile dye Remazol red and subsequent toxicological evaluation by cytotoxicity, genotoxicity and oxidative stress studies. Int. Biodeterior. Biodegrad. 65, 733-743. https:// doi.org/10.1016/j.ibiod.2011.04.003 (2011).

6. Lau, W. J. \& Ismail, A. F. Polymeri nanofiltration of membranes for textile dye wastewater treatment: preparation, performance, evaluation, transport modeling and fouling control-a review. Desalination 245, 321-348. https://doi.org/10.1016/j.desal.2007.12.058 (2009).

7. Zodi, S., Merzouk, B., Potier, O., Lapicque, F. \& Leclerc, J. P. Direct Red 81 dye removal by a continuous flow electrocoagulation/ flotation reactor. Sep. Purif. Technol. 108, 215-222. https://doi.org/10.1016/j.seppur.2013.01.052 (2013).

8. Wang, R., Cai, X. \& Shen, F. TiO2 hollow microspheres with mesoporous surface: superior adsorption performance for dye removal. Appl. Surf. Sci. 305, 352-358. https://doi.org/10.1016/j.apsusc.2014.03.089 (2014).

9. Sugiarto, A. T., Ito, S., Ohshima, T., Sato, M. \& Skalny, J. D. Oxidative decoloration of dyes by pulsed discharge plasma in water. J. Electrost. 58(1), 135-145. https://doi.org/10.1016/S0304-3886(02)00203-6 (2003).

10. Robinson, T., McMullan, G., Marchant, R. \& Nigam, P. Remediation of dyes in textile effluent: a critical review on current treatment technologies with a proposed alternative. Bioresour. Technol. 77(3), 247-255. https://doi.org/10.1016/s0960-8524(00)00080 $-8(2001)$.

11. Lourenco, N. D. et al. Comparing aerobic granular sludge and flocculent sequencing batch reactor technologies for textile wastewater treatment. Biochem. Eng. J. 104, 57-63. https://doi.org/10.1016/j.bej.2015.04.025 (2015).

12. Sarria, V., Parra, S., Invernizzi, M., Péringer, P. \& Pulgarin, C. Photochemicalbiological treatment of a real industrial biorecalcitrant wastewater containing 5-amino-6-methyl-2-benzimidazolone. Water Sci. Technol. 44, 93-101. https://doi.org/10.2166/ wst.2001.0259 (2001).

13. Rueda-Marquez, R. R., Sillanpaa, M., Pocostales, P., Acevedo, A. \& Manzano, M. A. Post-treatment of biologically treated wastewater containing organic contaminants using a sequence of $\mathrm{H}_{2} \mathrm{O}_{2}$ based advanced oxidation processes: photolysis and catalytic wet oxidation. Water Res. 71, 85-96. https://doi.org/10.1016/j.watres.2014.12.054 (2015).

14. Oller, I., Malato, S. \& Sanchez-Perez, J. A. Combination of advanced oxidation processes and biological treatments for wastewater decontamination-a review. Sci. Total Environ. 409, 4141-4166. https://doi.org/10.1016/j.scitotenv.2010.08.061 (2011).

15. Chougule, A. S., Jadhav, S. B. \& Jadhav, J. P. Microbial degradation and detoxification of synthetic dye mixture by Pseudomonas sp. SUK 1. Proc. Natl. A. Sci. India B 84, 1059-1068. https://doi.org/10.1007/s40011-014-0313-z (2014).

16. El Nemr, A., Hassan, M. A. \& Madkour, F. F. Advanced oxidation process (AOP) for detoxification of acid red 17 dye solution and degradation mechanism. Environ. Process. 5, 95-113. https://doi.org/10.1007/s40710-018-0284-9 (2018).

17. Chen, C. C., Wu, P. S. \& Chung, Y. C. Coupled biological and photo-Fenton pretreatment system for the removal of di-(2-ethylhexyl) phthalate (DEHP) from water. Bioresour. Technol. 100, 4531-4534. https://doi.org/10.1016/j.biortech.2009.04.020 (2009).

18. Vilar, V. J. P. et al. Treatment of a sanitary landfill leachate using combined solar photo-Fenton and biological immobilized biomass reactor at a pilot scale. Water Res 45, 2647-2658. https://doi.org/10.1016/j.watres.2011.02.019 (2011).

19. Kalme, S., Ghodake, G. \& Govindwar, S. Red HE7B degradation using desulfonation by Pseudomonas desmolyticum NCIM 2112. Int. Biodeterior. Biodegrad. 60(4), 327-333. https://doi.org/10.1016/j.ibiod.2007.05.006 (2007).

20. Kalyani, D. C., Telke, A. A., Dhanve, R. S. \& Jadhav, J. P. Ecofriendly biodegradation and detoxification of reactive red 2 textile dye by newly isolated Pseudomonas sp. SUK1. J. Hazard. Mater. 163, 735-742. https://doi.org/10.1016/j.jhazmat.2008.07.020 (2009).

21. Muñoz, I., Rieradevall, J., Torrades, F., Peral, J. \& Doménech, X. Environmental assessment of different solar driven advanced oxidation processes. Sol. Energy 79, 369. https://doi.org/10.1016/j.solener.2005.02.014 (2005).

22. Harrelkas, F. et al. Photocatalytic and combined anaerobic-photocatalytic treatment of textile Dyes. Chemosphere 72, 1816-1822. https://doi.org/10.1016/j.chemosphere.2008.05.026 (2008).

23. Thanavel, M. et al. Combined biological and advanced oxidation process for decolorization of textile dyes. SN Appl. Sci. 1, 97. https ://doi.org/10.1007/s42452-018-0111-y (2019).

24. Ghoreishi, S. M. \& Haghighi, R. Chemical catalytic reaction and biological oxidation for treatment of non-biodegradable textile effluent. Chem. Eng. J. 95, 163-169. https://doi.org/10.1016/S1385-8947(03)00100-1 (2003).

25. Tantak, N. P. \& Chaudhari, S. Degradation of azo dyes by sequential Fenton's oxidation and aerobic biological treatment. J. Hazard. Mater. 136, 698-705. https://doi.org/10.1016/j.jhazmat.2005.12.049 (2006).

26. Lodha, B. \& Chaudhari, S. Optimization of Fenton-biological treatment scheme for the treatment of aqueous dye solutions. J. Hazard. Mater. 148, 459-466. https://doi.org/10.1016/j.jhazmat.2007.02.061 (2007).

27. Alvares, A. B. C., Diaper, C. \& Parsons, S. A. Partial oxidation by ozone to remove recalcitrance from wastewaters-a review. Environ. Technol. 22, 409-427. https://doi.org/10.1080/09593332208618273 (2001).

28. Parshetti, G., Kalme, S., Saratale, G. \& Govindwar, S. Biodegradation of malachite green by Kocuria rosea MTCC 1532. Acta Chim. Slov. 53, 492-498 (2006).

29. Senthil-Kumar, S. et al. Bioinformatics aided microbial approach for bioremediation of wastewater containing textile dyes. Ecol. Inform. 31, 112-121. https://doi.org/10.1016/j.ecoinf.2015.12.001 (2016).

30. Association, A. P. H. Standard Methods for the Examination of Water and Wastewater 20th edn. (APHA-AWWA-WEF, Washington, DC, USA, 1998).

31. Jadhav, U. U., Dawkar, V. V., Tamboli, D. P. \& Govindwar, S. P. Purification and characterization of veratryl alcohol oxidase from Comamonas sp. UVS and its role in decolorization of textile dyes. Biotechnol. Bioprocess Eng. 14, 369-376. https://doi.org/10.1007/ s12257-008-0300-4 (2009).

32. Hatvani, N. \& Mecs, I. Production of laccase and manganese peroxidase by Lentinus edodes on malt containing by product of the brewing process. Process Biochem. 37, 491-496. https://doi.org/10.1016/S0032-9592(01)00236-9 (2001).

33. Kurade, M. B., Waghmode, T. R., Tamboli, D. P. \& Govindwar, S. P. Differential catalytic action of Brevibacillus laterosporus on two dissimilar azo dyes Remazol red and Rubine GFL. J. Basic Microbiol. 53(2), 136-146. https://doi.org/10.1002/jobm.201100402 (2013).

34. Phugare, S., Patil, P., Govindwar, S. \& Jadhav, J. Exploitation of yeast biomass generated as a waste product of distillery industry for remediation of textile industry effluent. Int. Biodeter. Biodegrad. 64, 716-726. https://doi.org/10.1016/j.ibiod.2010.08.005 (2010).

35. Bankole, P. O., Adekunle, A. A., Jeon, B.-H. \& Govindwar, S. P. Novel cobiomass degradation of NSAIDs by two wood rot fungi, Ganoderma applanatum and Laetiporus sulphureus: ligninolytic enzymes induction, isotherm and kinetic studies. Ecotox. Environ. Safe. 203, 110997. https://doi.org/10.1016/j.ecoenv.2020.110997 (2020).

\section{Acknowledgements}

MT hereby expresses profound thanks to Science and Engineering Research Board (SERB), Department of Science and Technology, Government of India, New Delhi, for funding the research project (Ref. No: SR/ FT/ LS - 121/ 2011 Dt. 29.05.2012) under Fast Track Scheme for Young Scientists. The authors are grateful to the 
Director, Principal and the Secretary of National College (Autonomous), Tiruchirappalli, India, for their technical and administrative support and encouragement towards the success of the project.

\section{Author contributions}

M.T.: Conceptualization, Experimental design, Methodology, Manuscript Original Draft, Drew Figs. 1 and 3 with Graphpad Prism Version 8 while Fig. 6 was drawn with ChemSketch software version 11.02. and inserted images obtained directly from UV-Vis Spectrophotometer and FT-IR machine in the manuscript. POB: Statistical analyses, Compilation, Review and Editing of Manuscript Original Draft. RS: Revision, Vetting and Editing of Manuscript Original Draft. SPG: Review and Editing. SKS: Review and Editing.

\section{Competing interests}

The authors declare no competing interests.

\section{Additional information}

Correspondence and requests for materials should be addressed to P.O.B.

Reprints and permissions information is available at www.nature.com/reprints.

Publisher's note Springer Nature remains neutral with regard to jurisdictional claims in published maps and institutional affiliations.

(c) (i) Open Access This article is licensed under a Creative Commons Attribution 4.0 International License, which permits use, sharing, adaptation, distribution and reproduction in any medium or format, as long as you give appropriate credit to the original author(s) and the source, provide a link to the Creative Commons licence, and indicate if changes were made. The images or other third party material in this article are included in the article's Creative Commons licence, unless indicated otherwise in a credit line to the material. If material is not included in the article's Creative Commons licence and your intended use is not permitted by statutory regulation or exceeds the permitted use, you will need to obtain permission directly from the copyright holder. To view a copy of this licence, visit http://creativecommons.org/licenses/by/4.0/.

(C) The Author(s) 2020 